were not observed for non-abdominal surgery, but only 30 infections occurred in this group.

The difference between the proportion of our patients scoring 0 in the SENIC index, $16 \%$, and that of Haley et $\mathrm{al}^{4}$ and Culver et $\mathrm{al}^{3}{ }^{3} 46 \%$ to $47 \%$, can be explained easily: our study was performed on patients admitted to a general surgery service, whereas the SENIC study and the NNIS study were based on patients admitted to all surgical services. In our study population, 1,187 patients (80\%) underwent abdominal surgery, and 125 of them became infected (10.5\%). A similar rate of infection was found for nonabdominal surgery $(30 / 296=10.1 \%)$. The fact that one of the variables (abdominal surgery) scored in the SENIC index did not behave as a risk factor for surgical-site infection in our population may be one explanation of why the SENIC index showed a lower predictive ability than did the NNIS index. However, in biliary tract surgery, where this factor is obviated (all patients underwent abdominal surgery), the NNIS index did show a better predictive ability than the SENIC index. Nonetheless, one should be cautious in drawing conclusions on analyses done on subgroups with small sample sizes.

We have no explanation for the lower risk of infection observed in the highest category of the NNIS index (Table 3). However, only nine patients scored 3 in the NNIS index; this result may be a fluke of small sample size. Similarly, the decreasing infection risk with higher scores of the NNIS index seen for a SENIC level $\geqslant 3$ (Table 4) simply may reflect the fact that only 43 patients had a SENIC index $\geqslant 3$, and they were divided among three categories of the NNIS index.

In conclusion, our results suggest that the NNIS index is better than the SENIC index for discriminating and predicting the risk of surgicalwound infection.

\section{REFERENCES}

1. National Nosocomial Infections Surveillance System. Nosocomial infection rates for interhospital comparison: limitations and possible solutions. Infect Control Hosp Epidemiol 1991;10:609-621.

2. Haley RW. Nosocomial infections in surgical patients: developing valid measures of intrinsic patient risk. Am J Med 1991;91(suppl 3B):145S-151S.

3. Culver DH, Horan RC, Gaynes RP, et al. Surgical wound infection rates by wound class, operative procedure, and patient risk index. Am J Med 1991;91(suppl 3B):152S-157S.

4. Haley RW, Culver DH, Morgan WM, White JW, Emori TG, Hooton TM. Identifying patients at high risk of surgical wound infection: a simple multivariate index of patient susceptibility and wound contamination. Am J Epidemiol 1985;121:206-215.

5. McCabe WR, Jackson GG. Gram-negative bacteremia, II: clinical, laboratory and therapeutic observations. Arch Intern Med $1962 ; 110: 856-864$

6. Garner JS, Jarvis WR, Emori TG, Horan TC, Hughes JM. CDC definitions for nosocomial infections. Am J Infect Control 1988;16:128-140.

7. Haley RW, Quade D, Freeman H, Bennet J, the CDC SENIC Planning Committee. Appendix E. Algorithms for diagnosing infections. Am J Epidemiol 1980;111:635-643.

8. Mantel N. Chi-square tests with one degree of freedom: extensions of the Mantel-Haenszel procedure. J Am Stat Assoc 1963;58:690-700.

9. Gross PA. Striving for benchmark infection rates: progress in control for patient mix. Am J Med 1991;91 (suppl 3B):16S-20S.

10. Scheckler WE. Surgeon-specific wound infection rates-a potentially dangerous and misleading strategy. Infect Control Hosp Epidemiol 1988;9:145-146.

\title{
HCV Transmission by Tattooing
}

\section{by Gina Pugliese, RN, MS Martin S. Favero, PhD}

Dr. Sun Dian-Xing and colleagues from Bethune International Peach Hospital in Shiajiazhuang, China, reported three cases of hepatitis $\mathrm{C}$ virus $(\mathrm{HCV})$ infection from cosmetic tattooing. The patients were women aged 21 to 26 years with a history of tattooing of their eyebrows and eyelids in beauty parlors in China within days before onset of disease. They all had gastrointestinal symptoms and raised serum alanine aminotransferase and bilirubin. HCV antibodies (second-generation ELISA) and HCV RNA (nested PCR) were positive in all three cases. Liver biopsy in one patient showed acute hepatitis. None of the patients had a history of blood transfusions or intravenous drug abuse. One patient was single, and the spouses of the other two cases were anti-HCV negative.

The authors note that it is fashionable for women in China to tattoo their eyebrows and eyelids. In most beauty parlors, tattooing needles are nondisposable and only disinfected with $70 \%$ alcohol. Tattooing has been implicated in the transmission of other bloodborne pathogens, and this report highlights the need for scrupulous attention to sterilization or disposal of needles.

FROM: Dian-Xing S, Fu-Guang Z, Yun-Qin G, De-Sheng XI. Hepatitis C transmission by cosmetic tattooing in women. Lancet 1996;347:541. 